\title{
Factors Influencing the Quality of Mobile Applications
}

\author{
Alin ZAMFIROIU
}

Bucharest University of Economic Studies, Romania zamfiroiu@ici.ro

Mobile applications are becoming increasingly used. Mobile devices are becoming indispensable for the user. In the material are claiming the sales of mobile devices internationally and the use of mobile applications compared to traditional internet use on desktop systems for the United States. Are presented influences the quality of mobile applications and based on these influencing factors built a model of choice for optimal application of mobile applications and traditional desktop application. At the end of the material presented methods to increase quality by tracking the influence factors during the development of mobile applications.

Keywords: Mobile Application, Quality, Influencing Factors, Model, Mobile Device

\section{Mobile applications}

The mobile application is a set of coded instructions used by a mobile device to solve a problem. In [1], [2] the evolution of mobile devices sales in 1992-2013 is presented. This evolution highlighting the manufacturer who sold the most devices in each is presented in Table 1 .

Table 1. Annual sales by manufacturers (millions)

\begin{tabular}{|c|c|c|c|c|c|c|c|c|c|c|c|}
\hline Year & NEC & Nokia & Motorala & Apple & Ericsson & Samsung & Siemens & Alcatel & LG & HTC & RIM \\
\hline 1992 & 4 & 3 & - & - & - & - & - & - & - & - & - \\
\hline 1993 & - & 5 & $?$ & - & - & - & - & - & - & - & - \\
\hline 1994 & - & 9 & 12 & - & - & - & - & - & - & - & - \\
\hline 1995 & - & 13 & $?$ & - & - & - & - & - & - & - & - \\
\hline 1996 & - & 18 & $?$ & - & - & - & - & - & - & - & - \\
\hline 1997 & - & 23 & $?$ & - & - & - & - & - & - & - & - \\
\hline 1998 & - & 39 & 34 & - & 26 & 5 & - & - & - & - & - \\
\hline 1999 & - & 77 & 48 & - & 30 & 18 & - & - & - & - & - \\
\hline 2000 & - & 127 & 61 & - & 42 & 21 & 27 & - & - & - & - \\
\hline 2001 & - & 140 & 60 & - & 27 & 29 & 40 & - & - & - & - \\
\hline 2002 & 9 & 152 & 73 & - & 24 & 42 & 35 & 12 & 14 & - & - \\
\hline 2003 & 15 & 182 & 76 & - & 27 & 55 & 44 & 8 & 27 & - & - \\
\hline 2004 & - & 208 & 105 & - & - & 86 & 49 & - & 43 & - & 1 \\
\hline 2005 & - & 265 & 145 & - & 52 & 104 & - & - & 55 & - & 4 \\
\hline 2006 & - & 500 & 210 & - & 74 & 117 & 24 & - & 62 & - & - \\
\hline 2007 & 16 & 436 & 165 & 2.3 & 102 & 154 & - & - & 79 & - & 10 \\
\hline 2008 & - & 475 & 108 & 12 & 95 & 202 & - & - & 104 & - & 25 \\
\hline 2009 & 5 & 442 & 59 & 24 & 57 & 238 & - & - & 124 & 11 & 35 \\
\hline 2010 & - & 463 & 39 & 42 & 42 & 282 & - & 33 & 117 & 25 & 48 \\
\hline 2011 & - & 422 & 40 & 89 & 33 & 330 & - & - & 86 & 48 & 52 \\
\hline 2012 & - & 335.6 & - & 135.8 & - & 396.5 & - & - & 55.9 & 32.6 & - \\
\hline 2013 & - & 250.8 & - & 150.8 & 69 & 444.4 & - & - & 37.6 & - & - \\
\hline
\end{tabular}

Figure 1 shows the architecture of a mobile application. The first action taken by the user in the application requires authentication. If the user is authenticated for the first time has no activated the account must be activated by setting the account user name, password, and all the recognition and provisioning profile. After account activation user is redirected to the application menu. From this stage they can access their profile, and/or application modules. 


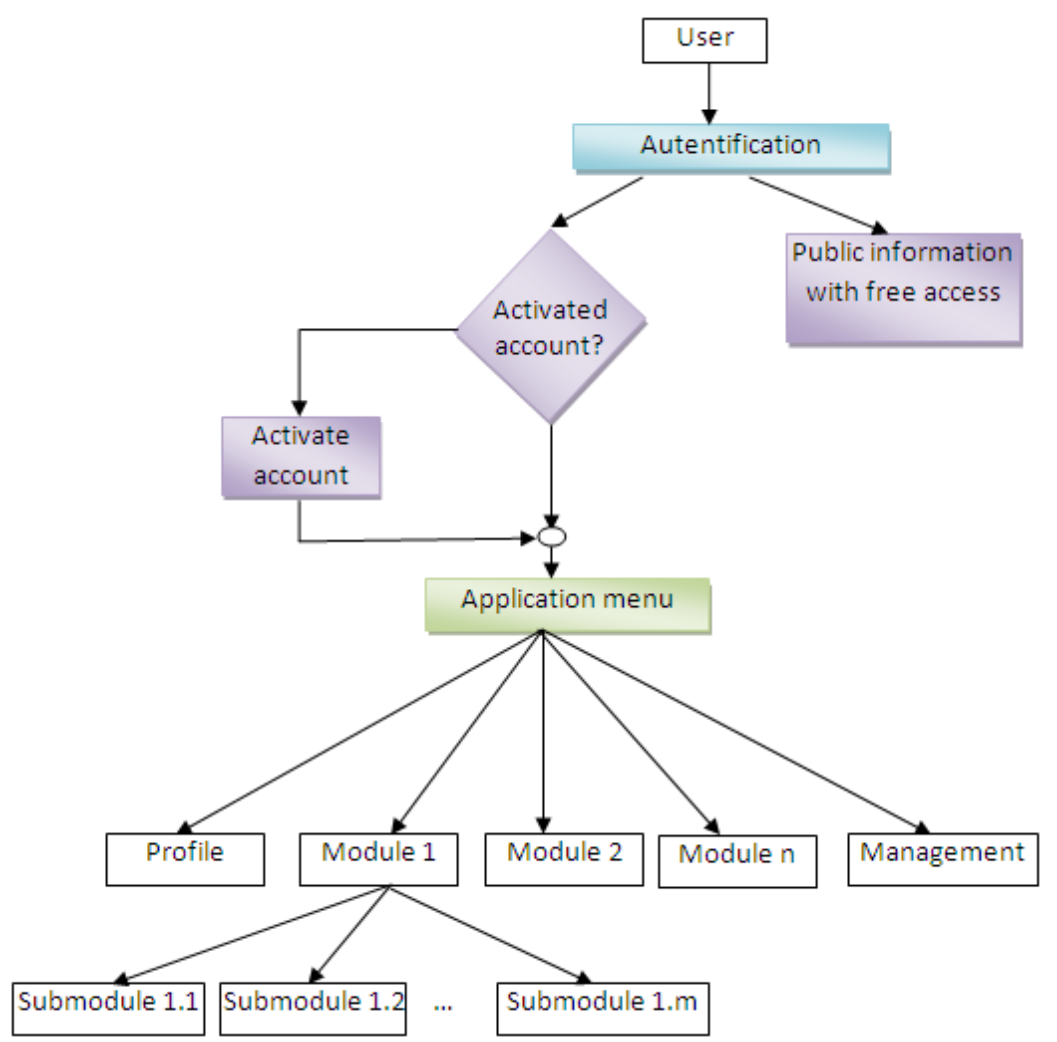

Fig. 1. Mobile application architecture

For each module and sub-modules are accessed hierarchically. If the user is an administrator in the application menu is available and management module for managing and administration of the application.

According to [3] time a spent using mobile application has increased in comparison with the time spent a traditional computer use. In January 2014 United States time spent in mobile applications has exceeded the time spent to access the internet on traditional computers. Thus it is found that mobile applications are a growing trend, Figure 2.

\section{Time Spent With the Internet, by Device, in the US \\ total minutes $(\mathrm{mm})$ per month \\ February 2013 - January 2014}

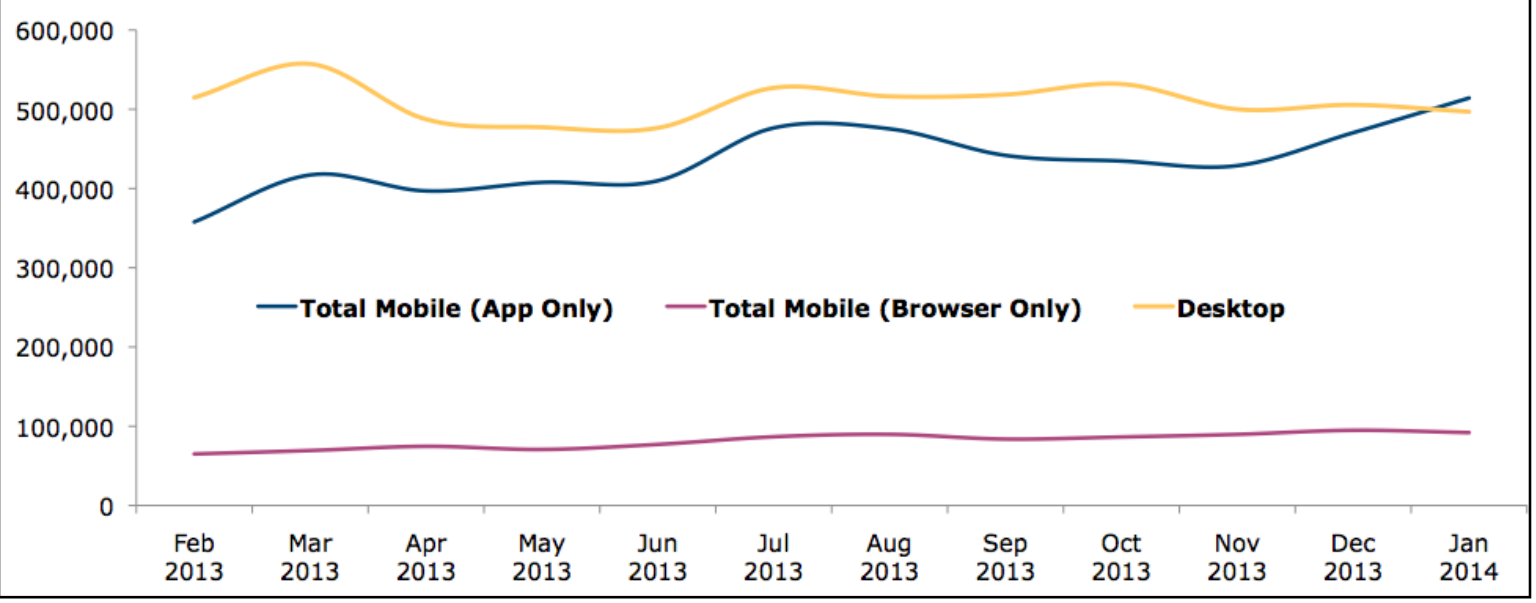

Fig. 2. Time spent on mobile applications [3] 
These uses also reflect the quality of the applications used. As time spent on mobile applications increased, the quality of these applications must be increase too.

\section{Factors of Influence}

On the quality of mobile applications have a big influence factors acting on mobile applications and mobile devices.

Factors of influence are of two types:

- external application and present through indirect influence on the quality of the application;

- internal application pertaining to the application and how it was carried out by the developer.

External factors influencing the quality of mobile applications are:

- the involvement of the developer level in creating robust applications with a high level of quality; if the developer is not interested in the quality of the mobile applications created, they will not meet quality standards and have a low quality;

- users expectations for mobile applications, where the expectations are very high and the application does not meet their expectations, it is categorized as an application with low quality [5]; also where users have expectations and the application meets the minimum lot more user functions as expected, the application is seen as too complex, and many users will not use because of this complexity too high; so it is very important for the development of mobile applications to build highly targeted group and be taken into account during the development of the mobile application;

- the distribution way of the application is an important factor for the use of the mobile application because an application is not distributed properly not reach the users who need it to use; distribution is recommended to be done through specialized shops producers operating system for mobile devices such as Google Play for Android devices and stores device manufacturers such as Samsung Apps for all devices from Samsung manufacturer;

- battery life is a factor that influences the time you can spend in the application user without having to recharge the battery of the mobile device; if the user is away on a trip and do not have the possibility to recharge the mobile device the application cannot be used;

- RAM memory of the mobile device influences the speed with which the application runs;

- CPU processing power of the unit of mobile device that run the mobile application;

- memory on hard disk of the mobile device is important for applications that work with large volumes of data and saved locally on the mobile device.

Internal factors influencing the quality of mobile applications are:

- the source code influence the application execution mode, if the code contains many repetitive instructions the application is a slow and consumes a lot of resources;

- used technologies for application development, if they are old technology cannot be run on mobile devices so new and fresh and the application will not be used by anyone [6], [7];

- commands rapidity has a very important role in determining the total time spent by user on the mobile application. So if speed is sufficiently high commands, the problem is solved in a short time and during interaction with the user application is reduced, which is not forced to interact with the application for a long time to solve the problem;

- the information volume provided is the amount of data and information displayed at one time on the mobile device via the; The small size of mobile devices brings great challenges in providing numerous user information. Must be borne in mind that if is provided 
a lot of information on reduced screen sizes as this information end up not being read or understood by the user.

- testing level influence the future behavior of the application by processing incidents and resource requirements for remedies. Testing is an important step in the process of software products [8], [9]. Each of the items has a greater influence on the quality and lower mobile applications and on their use.

Table 2. Influencing factors on mobile applications quality

\begin{tabular}{|c|c|}
\hline Factor & $\begin{array}{c}\text { Level of influence } \\
\text { (low/high) }\end{array}$ \\
\hline The involvement of the developer level \\
\hline Users expectations \\
\hline The distribution way \\
\hline Battery life & \\
\hline RAM memory of the mobile device & \\
\hline CPU processing power & \\
\hline Memory on hard disk of the mobile device & \\
\hline The source code & \\
\hline Used technologies & \\
\hline Commands rapidity & \\
\hline The information volume provided & \\
\hline Testing level & \\
\hline
\end{tabular}

Table 2 highlights the level of influence of each factor on mobile applications.

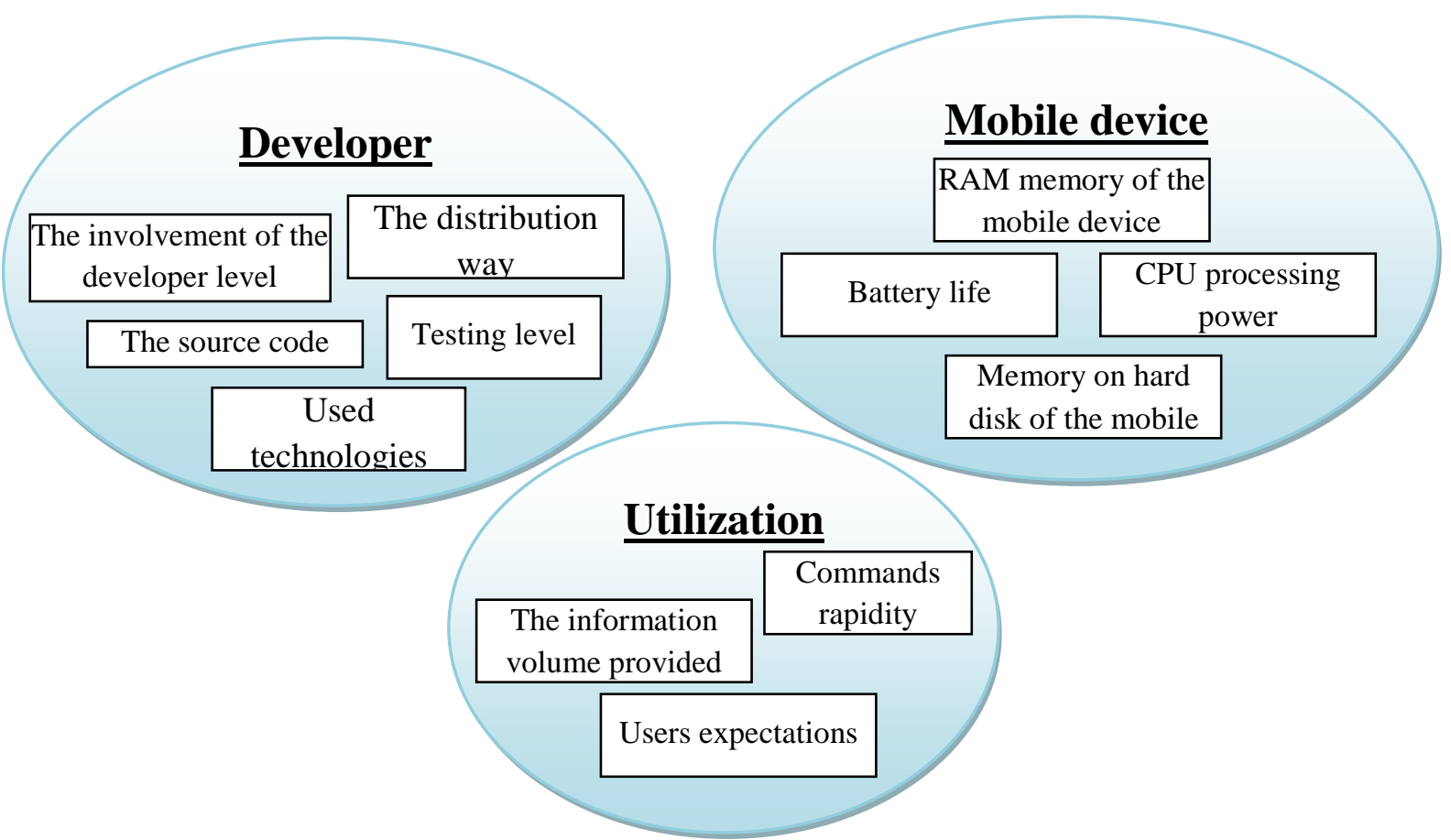

Fig. 3. Groups of influencing factors 
Influences factors belong to three major categories. Influencing factors related to mobile application developer, influence factors related to the mobile device that is

\section{Mobile Application /Desktop} Applications

For comparison of mobile applications with desktop applications, influence factors are run the application and its capabilities and influence factors related to the use of the mobile application. These groups are shown in Figure 3.

considered multi-criteria analysis criteria. Table 3 presents these criteria along with their type and weight set for each criterion.

Table 3. Model criteria

\begin{tabular}{|c|c|c|}
\hline Factor & Type & Weight \\
\hline The involvement of the developer level & $\max$ & 0,1 \\
\hline Users expectations & $\max$ & 0,15 \\
\hline The distribution way & $\max$ & 0,12 \\
\hline Battery life & $\max$ & 0,05 \\
\hline RAM memory of the mobile device & $\max$ & 0,05 \\
\hline CPU processing power & $\max$ & 0,05 \\
\hline Memory on hard disk of the mobile device & $\max$ & 0,02 \\
\hline The source code & $\max$ & 0,04 \\
\hline Used technologies & $\max$ & 0,12 \\
\hline Commands rapidity & $\max$ & 0,1 \\
\hline The information volume provided & $\max$ & 0,08 \\
\hline Testing level & $\max$ & 0,12 \\
\hline
\end{tabular}

These values are entered in MultiCrit applications and desktop applications. Figure application for multi-criteria analysis of the 4 presents the window from MultiCrit two types of applications: mobile application with all criteria included.

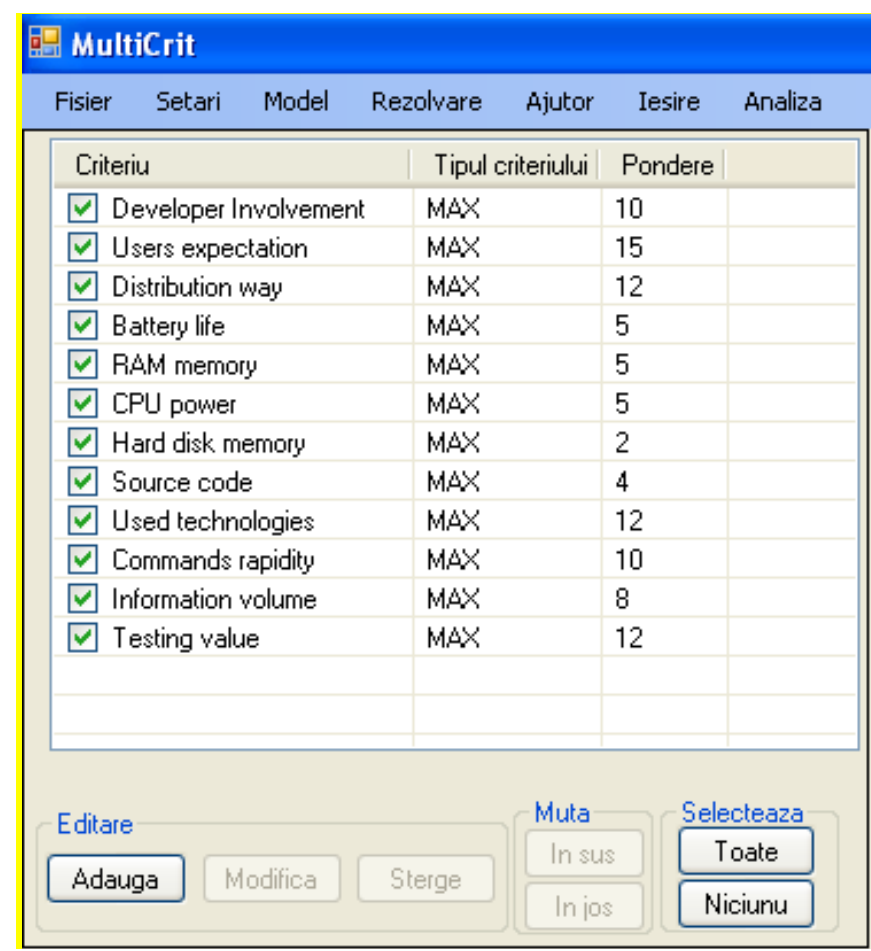

Fig. 4. Criteria entered in the MultiCrit application 
To solve it builds model decision matrix for shown in Table 4. the two types of applications. This matrix is

Table 4. Decision matrix

\begin{tabular}{|c|c|c|}
\hline Factor & $\begin{array}{c}\text { Desktop } \\
\text { applications }\end{array}$ & $\begin{array}{c}\text { Mobile } \\
\text { applications }\end{array}$ \\
\hline The involvement of the developer level & 9 & 9 \\
\hline Users expectations & 8 & 10 \\
\hline The distribution way & 3 & 5 \\
\hline Battery life & 10 & 7 \\
\hline RAM memory of the mobile device & 8 & 2 \\
\hline CPU processing power & 8 & 4 \\
\hline Memory on hard disk of the mobile device & 1000 & 100 \\
\hline The source code & 1 & 1 \\
\hline Used technologies & 0 & 9 \\
\hline Commands rapidity & 8 & 8 \\
\hline The information volume provided & 10 & 9 \\
\hline Testing level & 7 & \\
\hline
\end{tabular}

Based on the decision matrix software MultiCrit create and solve the model with Onicescu method, TOPSIS method and SAW methid- Simple Additive Weighting, the data and results are obtained out to be advantageous to use mobile applications at the expense of using desktop applications, Figure 5.

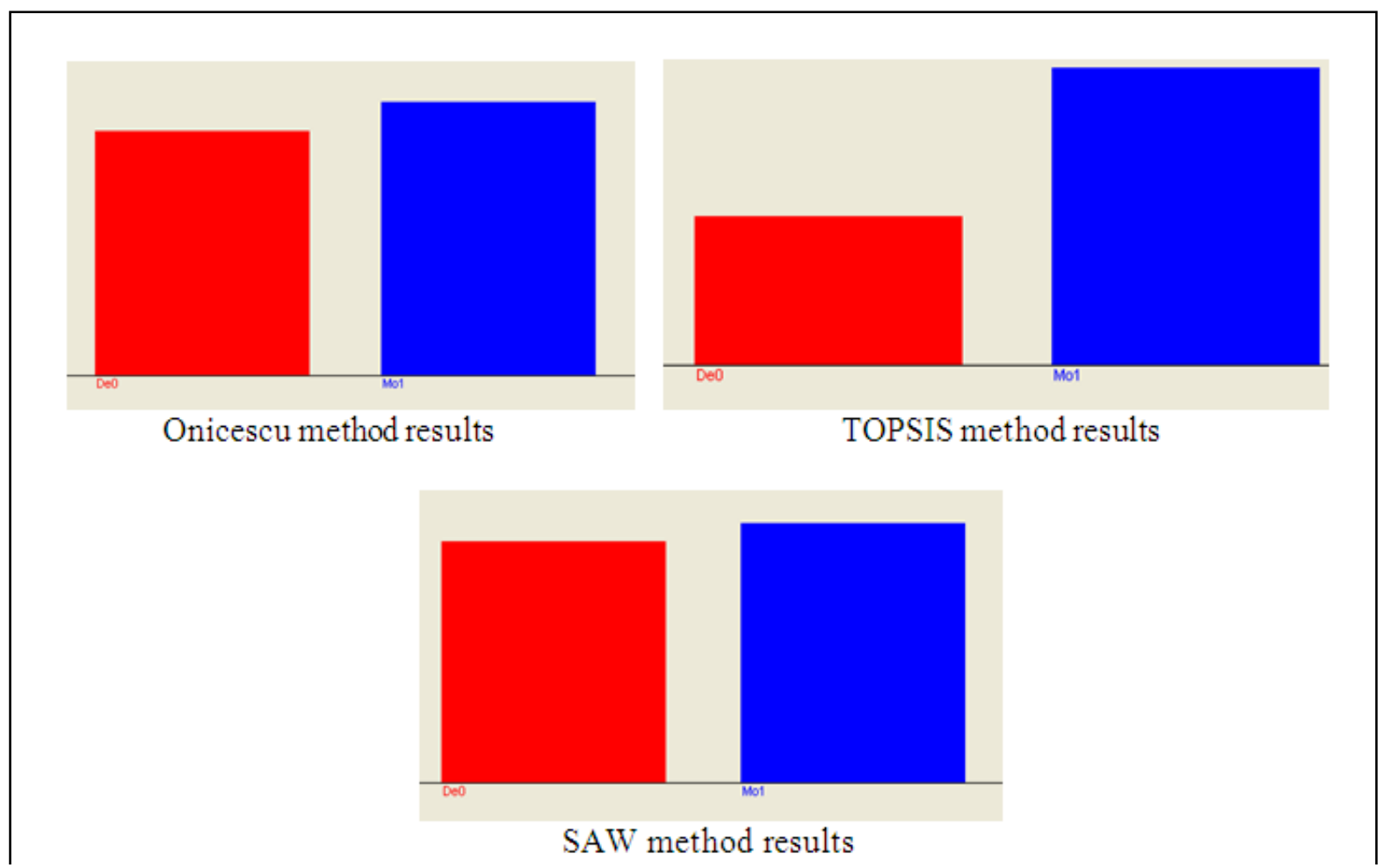

Fig. 5. Methods results

This demonstrates that increased use of longer than desktop applications. The time mobile applications reaching soon to take spent on mobile application is increased 
because a mobile application is an optimal solution between mobile and desktop applications.

\section{Increasing the Quality of Mobile} Applications
According to [4] when users find a website that does not meet his expectations or does not have a version for mobile devices no longer use it and do not recommend it to other persons, Figure 6.

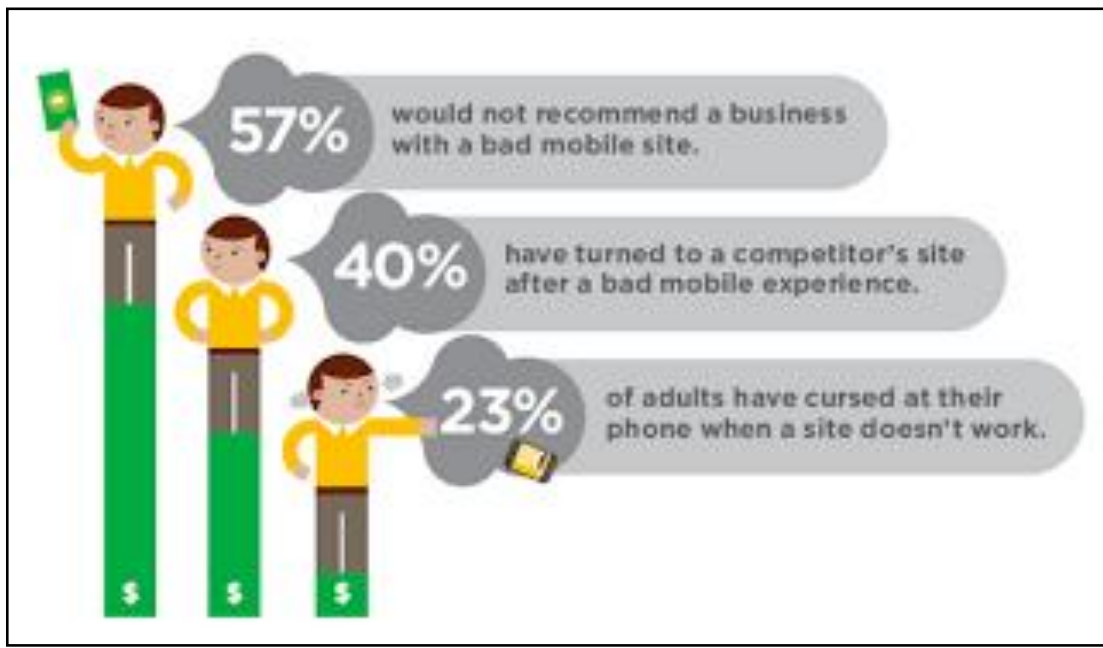

Fig. 6. Recommendation on web applications for mobile devices [4]

Such applications with high quality keeps customers loyal and they in turn recommend other persons application, increasing in this way the number of users. If the application has a low quality, users will never use nor recommend it to other people.

To increase the quality of mobile applications and their utilization among endusers have considered all factors influencing mobile applications. Ever since mobile application development should be followed to ensure the fulfillment of each feature and each influencing factor.

Similarly searching for quality assurance and tracking influence factors. Thus:

For the factor is achieved by surveys among users in the target group and seek implementation of the requirements and needs.

For the distribution way of the application to maximize the impact is recommended distribution through all available channels: both through specialist shops and through social networks or even be made a website where they can be downloaded. It is also recommended placing it in specialized shops because mobile devices are made with the default setting to not install applications from sources other than the manufacturer's shop.
Otherwise the user must modify these settings.

For all the influence factors related to mobile device, the only thing that can be done is that the description of the application to specify what devices is recommended, in this way for the devices which have battery life too short or low RAM or CPU processing power is reduced is not recommended to install that mobile application.

Influence factor represented by the source code is recommended as for readability feature that developers have a right to write proper code and mobile devices.

Used technology is recommended by current technology despite having trained for this application but the quality will increase their expense using obsolete technologies.

For the information volume provided mobile application developer must provide an adequate amount of information so that the user is satisfied with the information volume but also the presentation of this information.

\section{Conclusions}

Mobile devices have evolved allowing their use for solving any kind of problem. Their power computing, both in terms of 
processing power and available memory have greatly expanded. The availability of mobile operating systems has made application development process to be easy and thus led to a boom in mobile applications development. Important aspects are that the usage of mobile applications is increased a lot and exceeds the usage of desktop applications.

\section{References}

[1] http://en.wikipedia.org/wiki/List_of_bestselling_mobile_phones

[2] A. Zamfiroiu, M.L. Despa, "Reasons, Circumstances and Innovative Trends in Mobile Environments", Informatica Economica, vol. 17, nr. 2, 2013, pg 109118, ISSN: 1453-1305;

[3] http://www.marketingcharts.com/wp/ online/in-the-us-time-spent-with-mobileapps-now-exceeds-the-desktop-web41153/

[4] http://adwords.blogspot.ro/2012_05_01_. html

[5] L. Arhippainen, M. Tähti, "Empirical Evaluation of User Experience in Two
Adaptive Mobile Application Prototypes", Proceedings of the 2nd International Conference on Mobile łdots (January 2003).

[6] P. Pocatilu, C. Boja, C. Ciurea, "Syncing Mobile Applications with Cloud Storage Services", Informatica Economică , Vol. 17, No. 2/2013, pp. 96-108.

[7] M. Popa, "Considerations Regarding the Cross-Platform Mobile Application Development Process", Economy Informatics, Vol. 13 No. 1/2013, pp. 64 72 ,

[8] C. Boja, M. Doinea, P. Pocatilu, "Impact of the Security requirements on Mobile Applications Usability", Economy Informatics, Vol. 13 No. 1/2013, pp. 64 72

[9] I. Ivan, C. Ciurea, A, Zamfiroiu, M. Despa, C. Sbora, E. Herteliu, "Software Testing, Cybernetic Process", The Eighth International Conference on Economic Cybernetic Analysis: Development and Resources (DERS 2013), Bucharest, Romania, November 1-2, 2013, ISSN 2247-1820, ISSN-L 2247-1820.

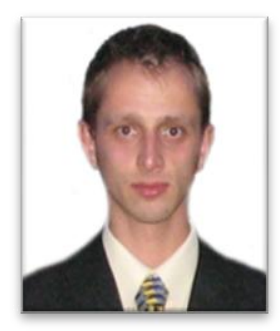

Alin ZAMFIROIU has graduated the Faculty of Cybernetics, Statistics and Economic Informatics in 2009. In 2011 he has graduated the Economic Informatics Master program organized by the Academy of Economic Studies of Bucharest. Currently he works like a research assistant at "National Institute for Research \& Development in Informatics, Bucharest" and is PhD student in Economic Informatics at the Academy of Economic Studies. He has published as author and co-author of few journal articles and scientific presentations at conferences. 